\title{
Fibonacci-type tubular photobioreactor for the production of microalgae
}

\author{
Juan Pablo Díaz , Cristian Inostroza ${ }^{\mathrm{b}}$, F.G. Acién Fernández,* \\ ${ }^{a}$ Universidad Arturo Prat, Avda. Arturo Prat 21-20, Iquique, Chile \\ b Chemical Engineering Department, University of Almeria, Ctra. Sacramento, s/n, 04120 Almería, Spain
}

\section{A R T I C L E I N F O}

\section{Keywords:}

Microalgae

Photobioreactor

Tubular

Fibonacci

Biomass productivity

Photosynthetic efficiency

\begin{abstract}
A B S T R A C T
In this work, a new tubular photobioreactor design based on the Fibonacci equation is proposed. A small $6 \mathrm{~L}$ unit was evaluated indoors and a larger $250 \mathrm{~L}$ unit was evaluated outdoors; both units maintained the same concept and the same aspect ratio. To test the new design, the Arthrospira (Spirulina) platensis strain was used. The results show that the proposed design allows the temperature, $\mathrm{pH}$ and dissolved oxygen to be maintained within the optimal ranges recommended for the selected strain. Consequently, overheating was avoided, even under outdoor conditions, and the dissolved oxygen concentration remained below the $200 \%$ Sat limit. Modelling of the growth in both reactors demonstrated that cell performance was optimal under indoor and outdoor conditions, with outdoor maximal specific growth rates reaching 0.8 1/day. Moreover, under outdoor conditions, photosynthetic efficiency reached $8.3 \%$, thus confirming high light-utilization efficacy even at high irradiances when using this new photobioreactor design. Our work represents a first step in the development of this promising technology as an alternative to those presently used. Developing industrial-scale microalgae biotechnology requires more productive and effective photobioreactors capable of maximizing biomass productivity under high light conditions.
\end{abstract}

\section{Introduction}

Microalgae are a source of bioactive substances valued in various markets such as pharmaceuticals, nutraceuticals and the food industry [1]. To obtain these bioactive substances, suitable and controllable industrial production processes must be developed that meet the specific demands and regulations of these sectors. An example of this is the rapid development of microalgal biotechnology taking place in different countries such as France, The United States, China, Japan, Taiwan and Thailand, most related to microalgae production processes for food and functional food markets; in particular microalgae used in breads, yogurt and beverages, among others [2].

Although microalgae production is mainly performed in open raceway reactors, industrial facilities using tubular photobioreactors have also recently been built around the world. These reactors allow almost any microalgal strain to be produced, and more importantly, the biomass to be cultivated under more controlled conditions thus resulting in higher biomass quality while diminishing the risk of contamination. However, tubular reactors have certain drawbacks related to temperature control, optimal $\mathrm{CO}_{2}$ supply and oxygen removal, all dependent on light capture by the reactor [3-5]. It has been widely reported that inadequate temperatures in tubular photobioreactors reduce the growth of microalgae strains, given that the limits tolerated by most microalgae strains range from 10 to $40^{\circ} \mathrm{C}$ [6-9]. Regarding the $\mathrm{pH}$ level, carbon dioxide is usually injected on-demand to control it and to provide inorganic carbon, thus avoiding carbon limitation. The $\mathrm{pH}$ limits that most strains can tolerate range from 4 to 9 , except for cyanobacteria, which can tolerate up to $\mathrm{pH} 11[7,8,10]$. Regarding the amount of oxygen, excessive dissolved oxygen accumulation above $20 \mathrm{mg} / \mathrm{L}$ has also been demonstrated to reduce the photosynthesis rate of different microalgae strains significantly; above this value photorespiration can even take place $[7,8,11,12]$. All these parameters are modified in tubular photobioreactors as a function of the reactor design and the solar irradiance intercepted; thus, both the heat balance and the microalgae cell performance are dependent on the light captured by the tubes comprising the solar collector.

The light captured by the solar collector in tubular photobioreactors is dependent on their configuration, which includes the tube diameter and the tube's spatial distribution. The tube diameter influences the light gradient inside the tube, and therefore the light regime to which the cells are exposed inside the reactor. It has been reported that using small tube diameters and adequate flow velocities can improve photosynthetic performance by permitting light integration if light exposure frequencies higher than $1 \mathrm{~Hz}$ are reached [13]. Concerning the spatial

\footnotetext{
* Corresponding author.

E-mail address: facien@ual.es (F.G. Acién Fernández).
} 
distribution of the tubes, the challenge is to achieve optimal designs that maximize the amount of solar radiation intercepted but distributing it over a larger surface to avoid excess light which can cause photo-inhibition - this is the "light dilution" effect, which is mainly a function of the reactor's volume to surface (V/S) ratio [14]. Designing reactors with an optimal V/S ratio allows the system's light utilization efficiency to be improved and to increase the biomass yield, so reducing the biomass production cost by increasing the amount of biomass produced using the same resources. Accordingly, a wide range of tubular photobioreactor configurations have been proposed, such as the helical [15], double loop [16] and horizontally or vertically arranged wall systems [17]. The most commonly employed at the commercial scale is the wall configuration, which is currently being used mainly to produce Chlorella and Haematococcus [18] species. However, tubular photobioreactor designs must still be optimized to improve their performance by developing systems capable of maintaining the culture under optimal conditions (temperature, $\mathrm{pH}$ and dissolved oxygen) with minimal energy consumption and contamination risk [5,19].

In this paper, we propose a new photobioreactor embracing Fibonacci's geometry. This comes from observing the geometry of the photosynthetic organisms in their natural state, where the plant growth forms turns, spirals or coils; patterns classified as helical [20,21]. Plants develop varied leaf distribution geometries to optimize light absorption $[22,23]$. For this reason, logarithmic spiral designs are abundant in nature, as discovered by the mathematician Leonardo Fibonacci. From the physical standpoint, it has been found that spiral heat exchangers have greater heat transfer than straight tube heat exchangers because they possess a higher surface to volume ratio [24]. In this context, it is possible to consider photobioreactors as artificial photosynthetic trees. Hence, they need to be re-evaluated so as to explore new geometric forms, in which the spiral pattern could prove to be innovative and highly efficient.

The objective of this paper is to investigate a new configuration - a Fibonacci-type tubular photobioreactor based on a helical spiral. To do this, we analysed the irradiance captured by this reactor and the reactor's performance in producing Spirulina, under both indoor and outdoor conditions. Demonstrating this new reactor concept is a first step towards developing the proposed technology at a larger scale.

\section{Material and methods}

\subsection{Microorganisms and culture conditions}

The strain Arthrospira (Spirulina) platensis M2 (National Research Council of Florence, Italy) was used, a vacuolated thermophilic cyanobacterium that is resistant to high light intensities. Indoor growth experiments were performed using Guillard's f/2 culture medium [25] whereas for outdoor conditions, a culture medium prepared using fertilizers was used $\left(\mathrm{NaHCO}_{3}, 8.4 \mathrm{~g} / \mathrm{L}\right.$, sea salt $5.0 \mathrm{~g} / \mathrm{L}, \mathrm{KNO}_{3} 3.6 \mathrm{~g} / \mathrm{L}$, $\left(\mathrm{NH}_{4}\right)_{2} \mathrm{HPO}_{4} 0.4 \mathrm{~g} / \mathrm{L}, \mathrm{MgSO}_{4} 0.02 \mathrm{~g} / \mathrm{L}$, Fe-EDTA $\left.0.0016 \mathrm{~g} / \mathrm{L}\right)$ [26], this culture medium being checked to provide excess of nutrients.

\subsection{Design of the Fibonacci-type photobioreactor and operating conditions}

Experiments were carried out in two photobioreactors, a small $6 \mathrm{~L}$ unit evaluated under indoor conditions and a bigger $250 \mathrm{~L}$ pilot unit, evaluated under outdoor conditions. The conical design of the photobioreactor was developed based on the biometrical parameters of Argopecten purpuratus shells, which follow Fibonaccian geometry. Employing the criteria of maximum light exposure [27], a three-dimensional structure of the shell was modelled, and then improved upon by adjusting the overall geometry to the location where the installation was planned (in Tarapacá, Chile), Subsequently, the design was completed by designing the supporting structures for both the indoor and outdoor units (Fig. 1). The photobioreactor consists of a photoactive panel, a driving system for liquid circulation and a gas exchange tank.
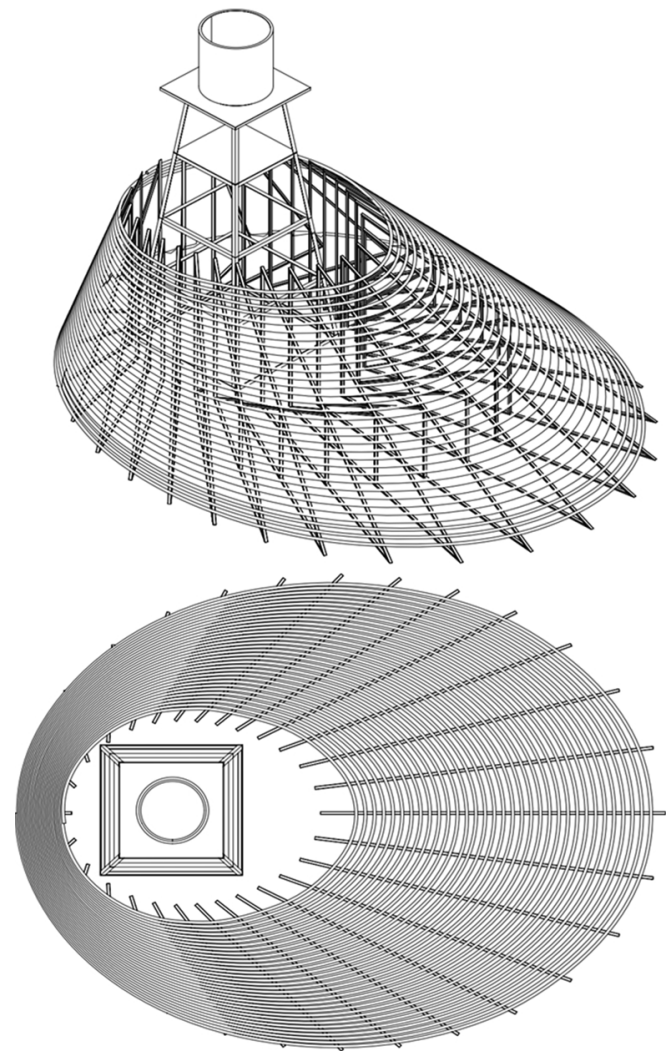

Fig. 1. Scheme of the Fibonacci-type tubular photobioreactor proposed. Tubes distribution and infraestructure required are showed.

Table 1

Geometric parameters of the indoor and outdoor photobioreactors used.

\begin{tabular}{llll}
\hline Photobioreactors & & & \\
\hline Parameters & Indoor & Outdoor & Unit \\
\hline Tube diameter & $\mathbf{0 . 0 1 2 6}$ & $\mathbf{0 . 0 2 5 2}$ & $\mathrm{m}$ \\
Long tube (Lt) & $\mathbf{4 7}$ & $\mathbf{5 0 1}$ & $\mathrm{m}$ \\
Land length (L) & $\mathbf{0 . 9 6}$ & $\mathbf{9}$ & $\mathrm{m}$ \\
Land width (W) & $\mathbf{0 . 8}$ & $\mathbf{7}$ & $\mathrm{m}$ \\
Surface of tube exposed to light (S $\left.\mathrm{S}_{\mathrm{t}}\right)$ & 1.86 & 39.66 & $\mathrm{~m}^{2}$ \\
Land occupied (S) & 0.768 & 63 & $\mathrm{~m}^{2}$ \\
Volume (V) & 0.008 & 0.330 & $\mathrm{~m}^{3}$ \\
S/V & 98 & 191 & $\mathrm{~m}^{2} / \mathrm{m}^{3}$ \\
V/S & 0.010 & 0.005 & $\mathrm{~m}^{3} / \mathrm{m}^{2}$ \\
St/V & 236.7 & 120.2 & $\mathrm{~m}^{2} / \mathrm{m}^{3}$ \\
\hline
\end{tabular}

The overall reactor dimensions are shown in Table 1.

The photoactive panel for both reactors $(6 \mathrm{~L}$ and $250 \mathrm{~L}$ ) is made of a single polyvinyl chloride tube, a transparent material resistant to ultraviolet radiation; likewise, it is resistant to $\mathrm{pH}$ levels from 3 to 14 and at temperatures from 0 to $45{ }^{\circ} \mathrm{C}$ can tolerate strongly saline water. The internal diameter of the tube is $0.012 \mathrm{~m}$ ( $0.5 \mathrm{inch})$ and $0.025 \mathrm{~m}$ ( 1 inch) for the indoor and outdoor units, respectively; the total length of the pipe being $47 \mathrm{~m}$ and $501 \mathrm{~m}$ for both scales, respectively. The volume of the gas exchange tank is $2 \mathrm{~L}$ for the laboratory reactor and $80 \mathrm{~L}$ for the outdoor prototype. The pipe is arranged in a spiral with the perimeter decreasing as it ascends, thus creating a truncated half-cone with a volume to surface ratio of 0.050 and $0.004 \mathrm{~m}^{3} / \mathrm{m}^{2}$ for the indoor and outdoor units, respectively. The liquid circulation in the indoor unit is performed using a magnetic pump located at the end of the solar collector, consisting of a flexible blade rotor without an inner cover that minimizes the shear stress to which the microalgae cells are exposed (Askol, Italy). In the case of the outdoor prototype, an air-lift system is 
used. The $\mathrm{CO}_{2}$ injection valve is located at the base of the half-cone to ensure that upward flow facilitate $\mathrm{CO}_{2}$ absorption. Under indoor conditions, the reactor was artificially illuminated at $175 \mu \mathrm{E} / \mathrm{m}^{2} \mathrm{~s}$ (photoperiod 16L:8D) using fluorescent lamps, whereas the $\mathrm{pH}$ was controlled at 9 by on-demand $\mathrm{CO}_{2}$ injection. The temperature was kept in the $30-35{ }^{\circ} \mathrm{C}$ range by controlling the temperature of the room where the reactor was located, whereas the dissolved oxygen concentration was not controlled as the reactor was designed (liquid velocity, reactor configuration and upward flow) to maintain the values within acceptable ranges.

Under outdoor conditions, the reactor was naturally illuminated with the solar irradiance being determined by the light availability present at the north-facing installations of the Universidad Arturo Prat (Iquique, Chile) where the reactor was located. In this case, the $\mathrm{pH}$ was also controlled by on-demand $\mathrm{CO}_{2}$ injection whereas the temperature and dissolved oxygen were not; the daily variation in irradiance and culture parameters being registered. To accomplish this, $\mathrm{pH}$ (1115001 4-STAR, Thermo Orion, UK), temperature and dissolved oxygen (55, YSI, USA) sensors were positioned at the end of the solar collector where extreme values are registered. In addition, environmental conditions such as air temperature, humidity and solar radiation were measured (Monitor 800027, Sper Scientific, USA; Radiometer 840029, Sper Scientific, USA).

\subsection{Light availability and photosynthetic efficiency}

The average irradiance to which the cultures were exposed (Iav) was calculated as a function of the irradiance on the reactor surface (Io), the extinction coefficient of the biomass (Ka,) the biomass concentration (Cb) and the light path in the reactor (p) (Eq. (1)) [28]. The Quantum yield $(\psi)$ is defined in microalgal cultures as the amount of biomass generated by the unit of radiation (usually a photon mole or Einstein) absorbed by the culture [29]. Since it represents the ratio of biomass generation to absorbed photon flux, it can be calculated by Eq. (2), as a function of the volumetric biomass productivity $(\mathrm{Pb})$ and the photon flux absorbed in the volume unit (Fvol). The photon flux absorbed throughout the reactor volume may be determined from the average irradiance on a culture volume basis, using Eq. (3). This coefficient can be converted to energy units as photosynthetic efficiency $\left(\psi_{\mathrm{KJ}}\right)$, by taking into account the average light energy used (kJ/E) (Eq. (4)). The bioenergetic yield ( $\psi$ ) quantifies the percentage of light energy that is converted to chemical energy; it can be calculated as the product of photosynthetic efficiency $\left(\psi_{\mathrm{KJ}}\right)$ using the biomass combustion heat $(\mathrm{Qb})(20 \mathrm{MJ} / \mathrm{kg})$. To evaluate any reactor, it is fundamental to estimate the quantum yield and photosynthetic efficiency, and in this way analyse the photobioreactor's light utilization efficiency [30,31].

$I a v=\frac{I o}{K a \cdot C b \cdot R}(1-\exp (-K a \cdot C b \cdot R))$

$\psi_{E}=\frac{P b}{F v o l}$

$\mathrm{Fvol}=\mathrm{Iav} \cdot \mathrm{Ka} \cdot \mathrm{Cb}$

$\psi_{K J}=\psi_{E} Q_{b}$

\subsection{Analytical methods}

Dry biomass was measured daily, for which $20 \mathrm{~mL}$ of culture sample was filtered, washed with $\mathrm{HCl}$ at $\mathrm{pH}=5$ and then dried in an oven at $60{ }^{\circ} \mathrm{C}$ for $12 \mathrm{~h}$ (in triplicate). Additionally, $10 \mathrm{~mL}$ of culture sample was taken to determine the absorbance of the cultures (Spectrophotometer SP 830 Plus, Metertech, Taiwan). Moreover, a daily observation was performed by microscope to determine the cell chain characteristics such as the number of turns, the filament shape, the chain length and the overall aspect of the cells.

\subsection{Software}

Data were processed using Microsoft Excel 2016. Statistical analysis was performed using Statgraphics 18. The 3-D structure of the photobioreactor was developed using SolidWorks; this software was also used to determine the solar light availability on the reactor surface.

\section{Results and discussion}

\subsection{Light capture and distribution of the conical reactor}

The available irradiance, the illuminated surface area and the reactor volume are the three most important factors in biomass production and when comparing photobioreactors [32]. In higher plants, their forms are very important, optimized to achieve the best photosynthetic performance. It is important to note that under outdoor conditions the photosynthetic process is subject to strong light saturation effects, and even to photo-inhibition. Consequently, nature has evolved helical growth strategies to dilute the flow of photons on the plant's photosynthetic surface $[22,33]$. The major factor determining the performance of any microalgae culture is light availability, a function of (i) the reactor location - determining the total radiation on the horizontal surface, and (ii) the reactor design - determining how much irradiance is collected with respect to that received on the horizontal surface. In raceway reactors, the total radiation available is limited to that received on the horizontal surface, but in tubular photobioreactors, more irradiance can be intercepted. To determine the irradiance intercepted by the Fibonacci-type tubular photobioreactor proposed, a simulation study was performed using SolidWorks. For this, the system geometry was built and then the energy flux received on the entire reactor surface was determined using this software (Fig. 2).

The results shows that the solar irradiance intercepted varies through the day based on the sun's position. Maximal irradiance is intercepted by the reactor surface when it is oriented towards the sun; in contrast, low irradiance is received by the surface on the opposite side to the sun's position. The maximal intercepted irradiance is up to 1.4times higher than that received on the horizontal surface (the red colour). Extending this analysis annually, the results shows that the overall solar radiation received on the reactor surface is more homogeneous in summer and spring; conversely, in winter and autumn, greater light gradients on the reactor surface occur (Fig. 3). The greater homogeneity in summer and spring favours optimal light utilization under these conditions, when excess light can even induce photo-
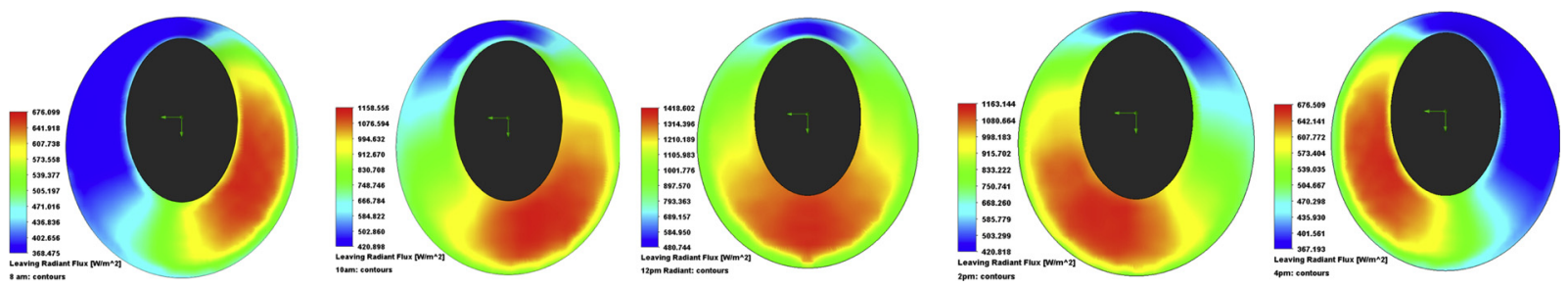

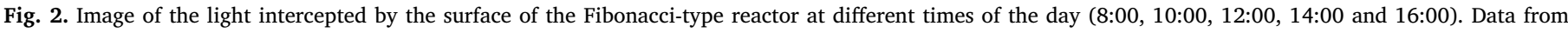
simulations performed using SolidWorks. 

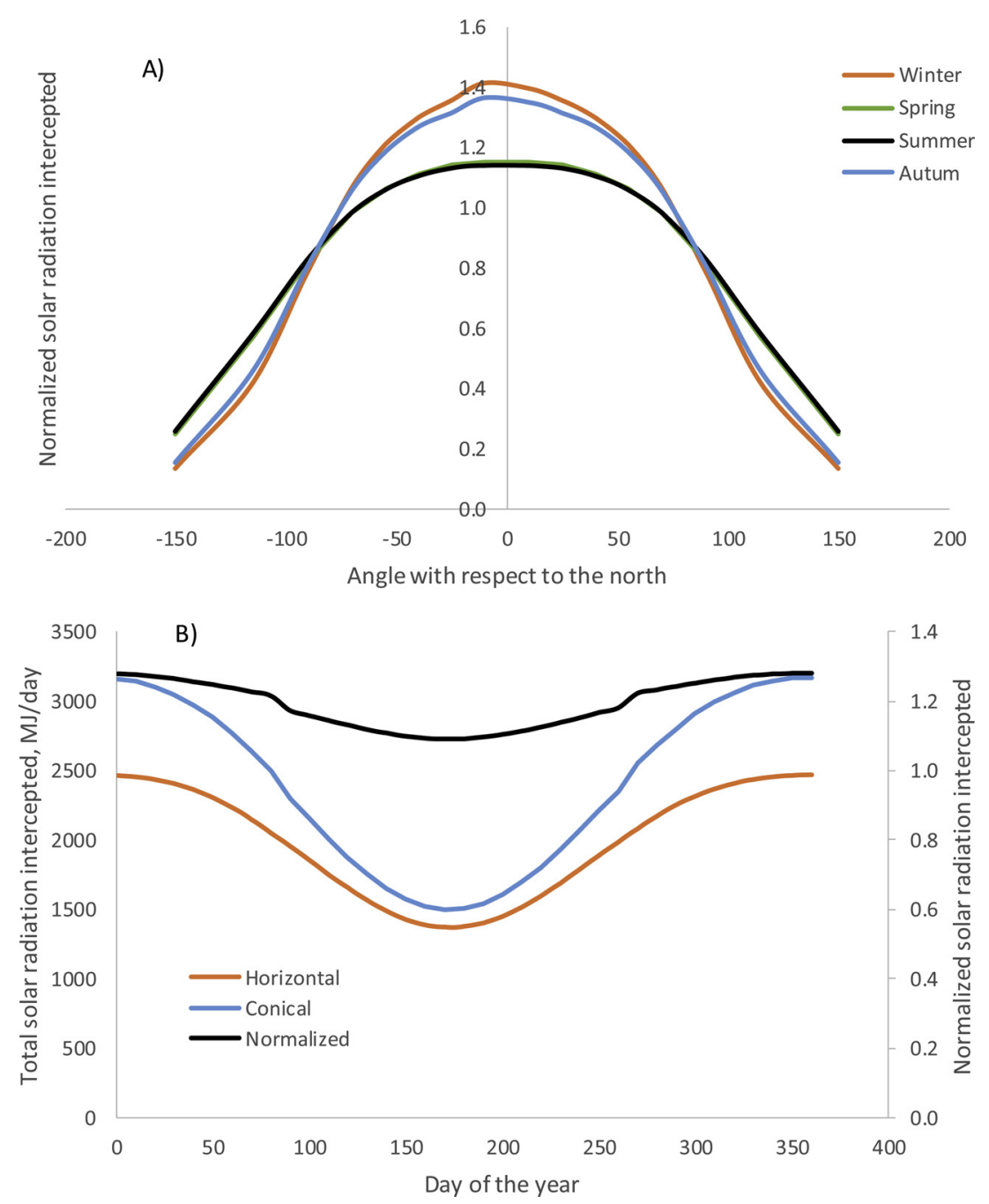

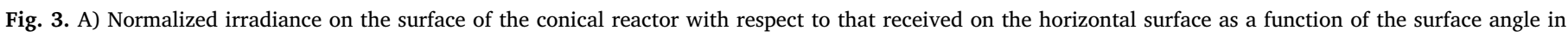

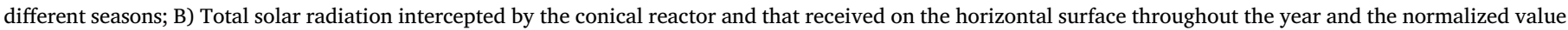
with respect to the horizontal one.

inhibition. With respect to the total intercepted solar radiation values, the results show that the proposed Fibonacci-type photobioreactor captured more light than the horizontal surface year round, and especially in the summer time, while distributing it in a more homogeneous form, as previously shown (Fig. 3).

On average, the solar radiation intercepted by the proposed reactor was $20 \%$ greater than that received on the horizontal surface. These figures are similar to those previously reported for flat-panel reactors [34] - vertical north/south-oriented flat-panel reactors exhibited the highest solar energy interception when compared to east/west-oriented flat-panel and horizontal reactors. Although the results vary depending on the location, at latitudes below $30^{\circ}$, the vertically arranged flat panel capture up to $10 \%$ more light than the horizontal surface, all year round [34]. The increased solar radiation intercepted by flat panels is also a function of the distance between them- for panels up to $1.7 \mathrm{~m}$ in height, the optimal distance is $1.5 \mathrm{~m}$ [35]. In vertically arranged tubular photobioreactors, the increase in intercepted irradiance is only $10 \%$, with the optimal distance between the solar loops of $1.7 \mathrm{~m}$-high vertically arranged tubes also being $1.5 \mathrm{~m}$ [36]. For the reactor proposed, this increase is up to $20 \%$; thus confirming the proposed design's greater capacity for capturing light.

\subsection{Influence of using a centrifugal pump for the liquid movement in the reactor}

In addition to light interception, in any reactor, the fluid-dynamic stress to which the cells are exposed is another major factor determining performance. It has been previously demonstrated that using inadequate impulsion systems damages the cells of various microalgae, such as Phaeodactylum, T-ISO, and Nannochloropsi,s amongst others $[37,38]$. In the conical reactor, both centrifugal and airlift systems can be used. The airlift system doesn't damage the cells whereas with centrifugal pumps, the existence of damage must be checked; in the case of Spirulina, the existence of adverse stress phenomena can easily be observed by the deterioration in the length of trichomes. In this case, the percentage of trichome fracture during the culture cycle was measured by observation with a microscope; the results confirming the existence of a real trichome cutting effect (Fig. 4).

Nonetheless, the trichomes were not completely damaged, the resulting fragments increasing in size until a stable trichome length was achieved (Fig. 4). In general, it has been noted that at the beginning of the culture, the trichomes are fragmented to a length equivalent to one third of their original size. Then, over the next four days, they grow rapidly to approximately $64 \%$ of their original size. Later, the trichome length reduces again, stabilizing at a final length which is approximately $45 \%$ of their original size. Spiral breakage in Spirulina cultures 

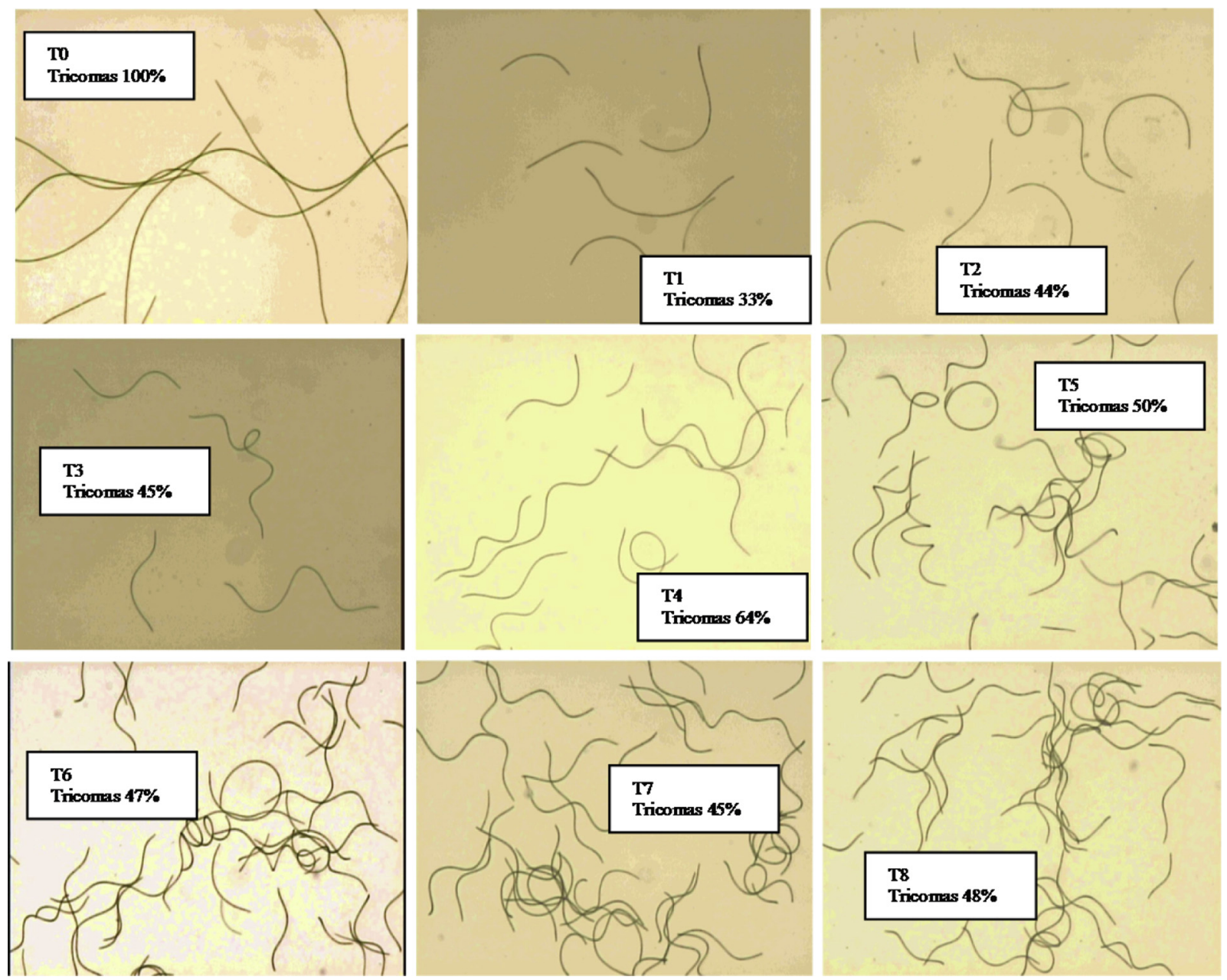

Fig. 4. Photographic sequence of the trichome sizes of Spirulina platensis produced in the conical reactor under laboratory conditions using a centrifugal pump for the liquid movement.

has also been linked to adverse UV radiation and the presence of reactive oxygen species (ROS) [39]. However, mechanical damage of spirals is the most recognized phenomena in Spirulina cultures, which also reduces culture performance and productivity if severe damage takes place [40].

\subsection{Performance of the Fibonacci-type photobioreactor under indoor conditions}

The main purpose of any reactor is to provide the optimal conditions required for the production of the target microorganism; in the case of microalgae, the main parameters are the light availability, temperature, $\mathrm{pH}$ and dissolved oxygen concentration to which the cells are exposed inside the reactor. With indoor reactors, the light availability and temperature are easily controlled while the $\mathrm{pH}$ and dissolved oxygen concentration are mainly a function of the reactor's mass transfer capacity. The results obtained under indoor conditions show that when providing a reactor surface irradiance of $175 \mu \mathrm{E} / \mathrm{m}^{2} \mathrm{~s}$ and a room temperature of $32{ }^{\circ} \mathrm{C}$, the culture temperature was $32 \pm 1{ }^{\circ} \mathrm{C}$ whereas the $\mathrm{pH}$ was maintained at $9.1 \pm 0.2$ by on-demand $\mathrm{CO}_{2}$ injection, and the maximal daily dissolved oxygen concentration was $130 \pm 10 \%$ Sat. (Fig. 5). In tubular photobioreactors, overheating is a major problem, with the culture temperature being $10-30{ }^{\circ} \mathrm{C}$ above the ambient temperature $[11,41]$. In the case of the proposed reactor, the increase was only $2{ }^{\circ} \mathrm{C}$ above the ambient temperature, although when using artificial light, overheating is far less relevant. Concerning the $\mathrm{pH}$, its control is crucial to maximize the performance of any microalgae culture as well as to prevent cell damage [11].

Data from the indoor reactor confirm that the proposed configuration allows the control of $\mathrm{pH}$ by on-demand $\mathrm{CO}_{2}$ injection, maintaining it at the defined setpoint value (9.0). Concerning the dissolved oxygen concentration, this is also a big issue in tubular photobioreactors dissolved oxygen concentrations above $200 \%$ Sat. significantly reduce the performance of most microalgae strains. In the proposed design, oxygen degassing was enough to keep the maximum daily dissolved oxygen concentration below $150 \%$ Sat., thanks to the upward flow and aeration in the tank reservoir. The upward flow of $\mathrm{CO}_{2}$ also facilitates $\mathrm{CO}_{2}$ absorption, with no $\mathrm{CO}_{2}$ bubbles remaining at the end of the solar collector. Consequently, three main objectives are achieved: (i) no $\mathrm{CO}_{2}$ released to the atmosphere, (ii) adequate $\mathrm{pH}$ control and (iii) reduced production costs.

Concerning culture growth, under laboratory conditions, a maximum biomass concentration of $1.85 \mathrm{~g} / \mathrm{L}$ was achieved at the end of the batch culture (10 days), whereas a maximal daily biomass productivity of $0.30 \mathrm{~g} / \mathrm{L}$ day was obtained at the end of linear growth phase (6 days) (Fig. 5). This biomass productivity was limited by the low irradiance $\left(175 \mu \mathrm{E} / \mathrm{m}^{2} \mathrm{~s}\right)$ on the reactor surface (artificial light provided by florescent tubes). To determine the average irradiance inside the culture, the simplified equation proposed by Molina can be used (Eq. (1)) [28], where the available light is calculated as a function of the total irradiance on the reactor surface (Io), considering the light attenuation caused by the biomass, which depends on the pipe radius (R) and incorporating a coefficient of light attenuation (Ka). Thus, the average irradiance inside the reactor reduces from 150 to $48 \mu \mathrm{E} / \mathrm{m}^{2} \mathrm{~s}$ during the 

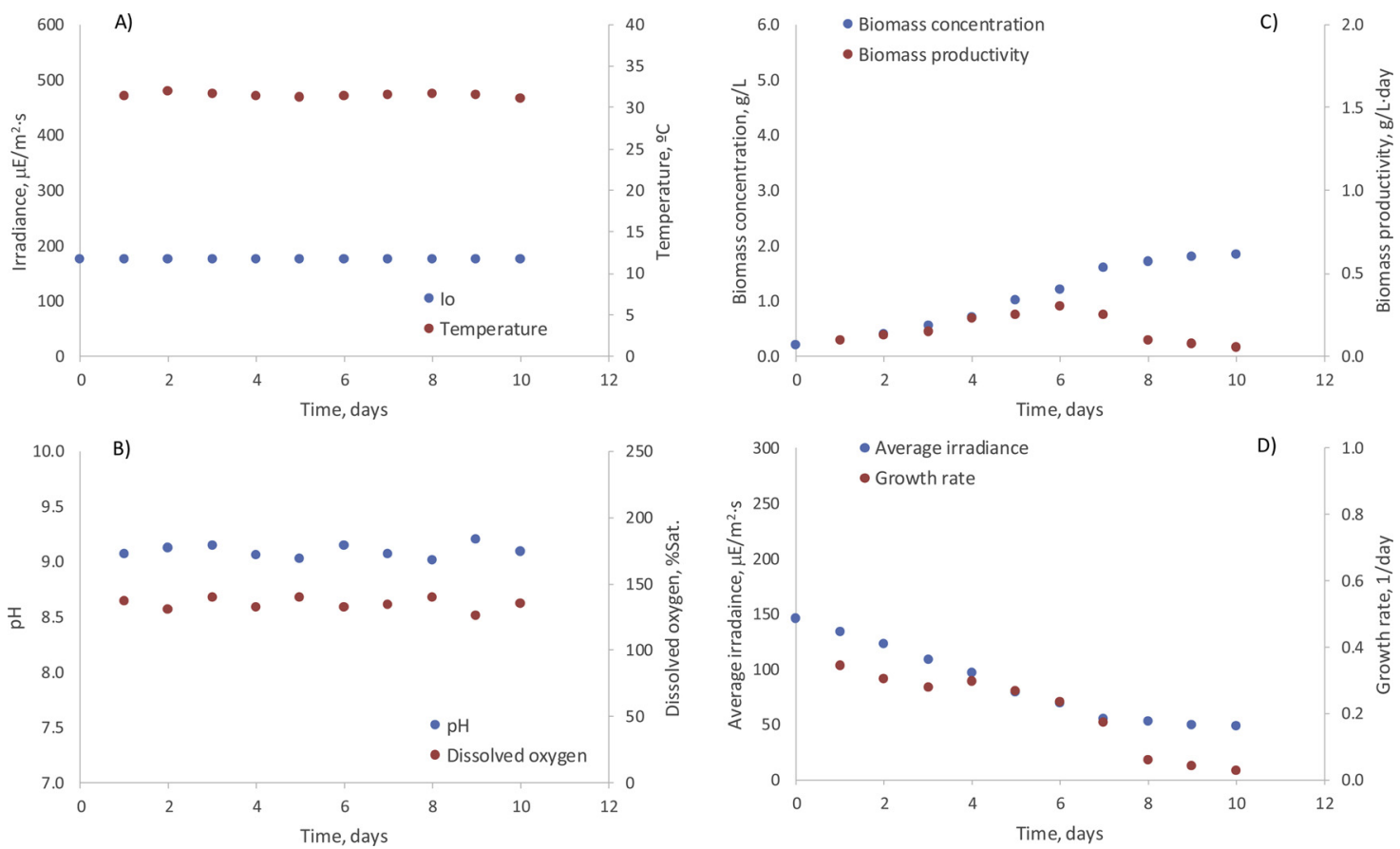

Fig. 5. Data from the batch culture of Spirulina platensis performed in the Fibonacci-type photobioreactor under indoor conditions.

batch culture as a consequence of increased biomass concentration in the culture, the lower light availability also reducing the specific growth rate from 0.35 to 0.031 /day during the batch culture (Fig. 5).

To evaluate the reactor's performance, the growth of the Spirulina platensis culture in the proposed photobioreactor was modelled, along with an evaluation of its photosynthetic performance (Fig. 6). By fitting the experimental results to the hyperbolic model [42], the model's characteristic parameter values were obtained. The maximal growth rate was 0.351 day whereas the form parameter value (n) was 2 and
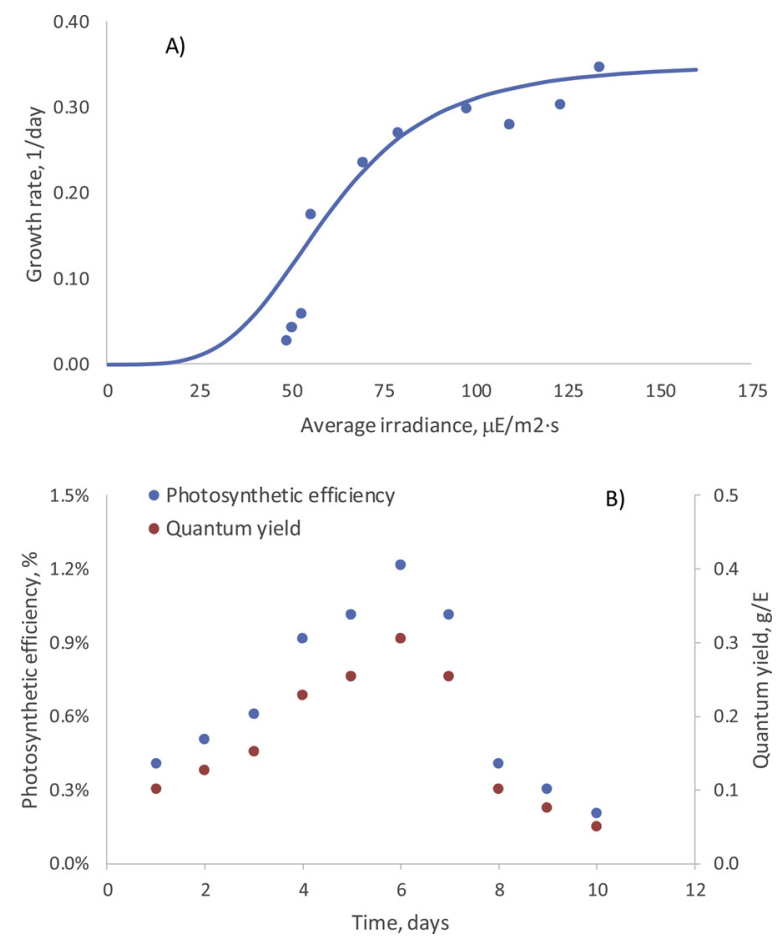

Fig. 6. Modelling of the growth rate and photosynthetic performance of Spirulina platensis cultures grown in the Fibonacci-type photobioreactor under indoor conditions. the irradiance constant was $60 \mu \mathrm{E} / \mathrm{m}^{2}$ s. These values agree with those previously reported for this strain and other highly productive strains, thus confirming that the cells were exposed to adequate conditions and their performance was maximal $[36,43,44]$. To demonstrate this, photosynthetic efficiency values up to $1.2 \%$, equivalent to $0.3 \mathrm{~g} / \mathrm{E}$, were determined (Fig. 6). These values are high, although they are lower to the maximal ones reported operating under low light conditions, at those conditions higher photosynthetic efficiency values being expected. Using outdoor bubble-column reactors, efficiencies up to $9.3 \%$ were reported, also using Spirulina platensis [45]. Indoors, photosynthetic efficiencies up to $8.3 \%$ were reported for Isochrysis galbana cultures at low irradiance, whereas increasing the irradiance decreased the values to $1.2 \%$ caused by light saturation or even light-inhibition phenomena [29].

\subsection{Performance of the Fibonacci-type photobioreactor under outdoor conditions}

To confirm the reliability of the proposed Fibonacci-type photobioreactor, a second unit was built and evaluated under outdoor conditions. In this case, the solar light was uncontrolled; during the experiment, the average solar irradiance in the light period ranged from 118 to $530 \mu \mathrm{E} / \mathrm{m}^{2} \mathrm{~s}$ due to the existence of sunny and cloudy days (Fig. 7). Despite these large variations in solar irradiance, the culture temperature ranged from 30 to $34^{\circ} \mathrm{C}$; so only a narrow temperature variation was observed and no overheating of the culture took place. Larger variations in $\mathrm{pH}$ and dissolved oxygen concentrations were observed due to the variations in solar irradiance - the $\mathrm{pH}$ ranged from 8.5 to 9.0 whereas the dissolved oxygen concentration ranged from 90 to $190 \%$ Sat. lower values being observed on cloudy days and larger values on sunny days (Fig. 7).

The adverse effect of high temperatures and dissolved oxygen concentrations has been previously reported in raceway reactors, this strongly reducing the performance of Spirulina platensis cultures [46]. Greater solar irradiance enhances the photosynthesis rate, with both $\mathrm{CO}_{2}$ demand and oxygen production increasing. The photobioreactor design proposed was capable of keeping both parameters under control, even under very demanding conditions, thus avoiding any adverse culture conditions for the cells. Evidence of this was the larger biomass 

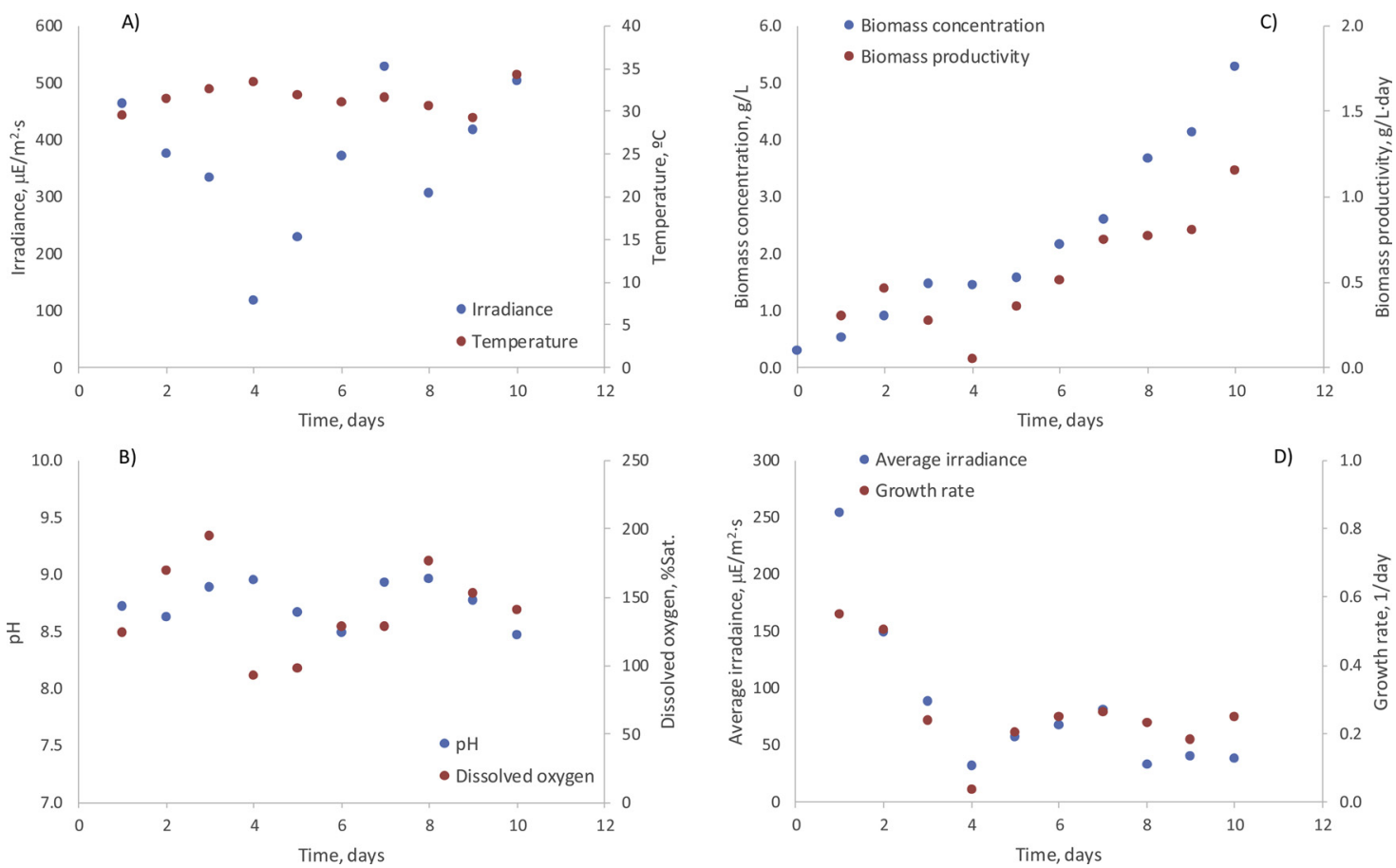

Fig. 7. Data from the batch culture of Spirulina platensis cultivated in the Fibonacci-type photobioreactor under outdoor conditions.

concentration achieved outdoors compared to under indoor conditions, with values up to $5.0 \mathrm{~g} / \mathrm{L}$ at the end of the batch culture (10 days); and for biomass productivity, value up to $1.1 \mathrm{~g} / \mathrm{L}$ day being obtained at the same time (10 days) (Fig. 7). Data from the outdoor reactor show that, after 10 days, the stationary phase was not yet achieved, light availability was still high enough to maintain linear growth (Fig. 7); the average irradiance values reduced from 250 to $40 \mu \mathrm{E} / \mathrm{m}^{2} \mathrm{~s}$ during the batch culture and, consequently, the specific growth rate reduced from 0.55 to 0.251 /day (Fig. 7). The data from the photobioreactor operated under outdoor conditions are similar to that reported in the literature; using the same strain, the biomass productivity in a coil reactor was $0.9 \mathrm{~g} / \mathrm{L}$ day, whereas in a near-horizontal reactor and in a two-plane reactor, the productivity value was $1.5 \mathrm{~g} / \mathrm{L}$ day [32]. Only when using direct sun-oriented flat-panel reactors did the biomass productivity increase to $2.1 \mathrm{~g} / \mathrm{L}$ day [32].

To evaluate the performance of the photobioreactor design proposed under outdoor conditions, we modelled the growth of Spirulina platensis culture, again calculating the photosynthetic performance (Fig. 8). The results show that the growth rate also fitted the hyperbolic model proposed, with values for the model's characteristic parameters being 0.61 /day at the maximal specific growth rate, 2 for the form parameter (n) and $60 \mu \mathrm{E} / \mathrm{m}^{2} \mathrm{~s}$ for the irradiance constant. These values are close to those determined under indoor conditions, except for the maximal growth rate, which was higher under outdoor conditions because of the greater light availability. These figures confirm the reliability of using the proposed photobioreactor under outdoor conditions, allowing the growth rate to be maintained in spite of the large variation in solar irradiance registered. Thus, the proposed technology allows us to achieve the main goal of any reactor technology - maintaining the performance of indoor cultures under outdoor conditions. Moreover, the photosynthetic efficiency values determined outdoors were equivalent to those measured indoors, achieving maximal values of $0.9 \%$; while quantum yield values up to $0.2 \mathrm{~g} / \mathrm{E}$ were also measured. These values are lower than maximal theoretical ones; indeed, even when considering those reported under indoor conditions [29,45,47].
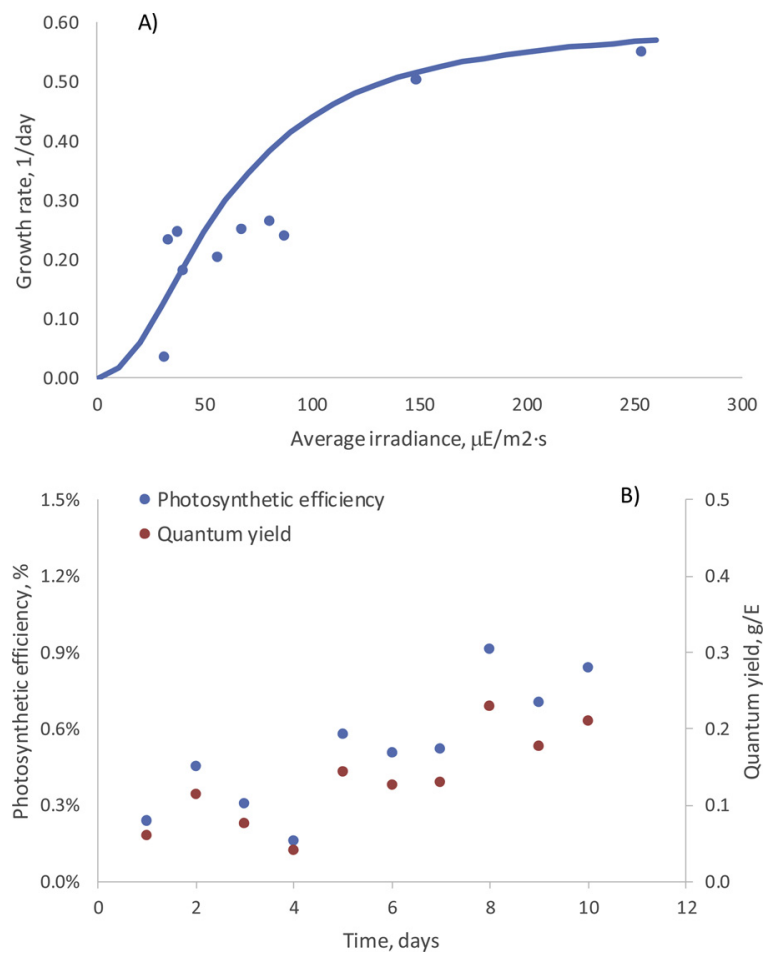

Fig. 8. Modelling of the growth rate and photosynthetic performance of Spirulina platensis cultures grown in the Fibonacci-type photobioreactor under outdoor conditions.

\section{Conclusions}

In this work, a new tubular photobioreactor design following the Fibonacci equation has been proposed. This new concept for the tubular photobioreactor has been evaluated at two scales, under indoor and outdoor conditions, with both maintaining the same aspect ratio. The results confirm that the proposed design allows up to a 1.4-times increase in intercepted solar radiation compared to that received on a 
horizontal surface, while providing optimal culture conditions for Spirulina platensis growth - moderate temperature, adequate $\mathrm{pH}$ and low dissolved oxygen concentration. Specific growth rates up to 0.551 /day and photosynthetic efficiencies up to $0.9 \%$ were measured outdoors, thus confirming the reliability of the proposed technology for producing microalgae. Nonetheless, the design and construction of this new photobioreactor type must still be improved; that said, this work demonstrates the potential of this new concept in improving microalgae culture productivity; a major challenge for the development of microalgae technology related to industry.

\section{Acknowledgements}

We wish to thank the members of the FONDEF project D04I1258: Marecela Avila, Claudio Brieba (R.I.P.), Elizabet Rojas, and Pablo Barria. The authors are also very grateful to: Attilio Gattavara and Masatoshi Futagawa for their noble cooperation, and especially to Claudio Brieba (R.I.P.) for being part of this dream.

\section{References}

[1] P. Spolaore, C. Joannis-Cassan, E. Duran, A. Isambert, Commercial applications of microalgae, J. Biosci. Bioeng. 101 (2006) 87-96 http://linkinghub.elsevier.com/ retrieve/pii/S1389172306705497.

[2] J.L. García, M. de Vicente, B. Galán, Microalgae, old sustainable food and fashion nutraceuticals, Microb. Biotechnol. 10 (2017) 1017-1024.

[3] F. Camacho-Rubio, F.G. Acién, J.A. Sánchez-Pérez, F. García-Camacho, E. MolinaGrima, Prediction of dissolved oxygen and carbon dioxide concentration profiles in tubular photobioreactors for microalgal culture, Biotechnol. Bioeng. 62 (1999) 71-86.

[4] A. Solimeno, R. Samsó, E. Uggetti, B. Sialve, J.P. Steyer, A. Gabarró, J. García, New mechanistic model to simulate microalgae growth, Algal Res. 12 (2015) 350-358.

[5] Z. Xing, X.W.L. Zong, On the engineering part of solar hydrogen production from water splitting: photoreactor design, Chem. Eng. Sci. 104 (2013) 125-146.

[6] J.P. Bitog, I.B. Lee, C.G. Lee, K.S. Kim, H.S. Hwang, S.W. Hong, I.H. Seo, K.S. Kwon, E. Mostafa, Application of computational fluid dynamics for modeling and designing photobioreactors for microalgae production: a review, Comput. Electron. Agric. (2011), http://linkinghub.elsevier.com/retrieve/pii/S0168169911000305.

[7] T.A.A. Costache, F.G.A. Fernández, F.G. Acien, M.M. Morales, J.M. FernándezSevilla, I. Stamatin, E. Molina, Comprehensive model of microalgae photosynthesis rate as a function of culture conditions in photobioreactors, Appl. Microbiol. Biotechnol. 97 (2013) 7627-7637.

[8] D. Ippoliti, C. Gómez, M.M. Morales-Amaral, R. Pistocchi, J.M.M. FernándezSevilla, F.G.G. Acién, Modeling of photosynthesis and respiration rate for Isochrysis galbana (T-Iso) and its influence on the production of this strain, Bioresour. Technol. 203 (2016) 71-79.

[9] M. Ras, J.P. Steyer, O. Bernard, Temperature effect on microalgae: a crucial factor for outdoor production, Rev. Environ. Sci. Biotechnol. 12 (2013) 153-164.

[10] Y. Bao, M. Liu, X. Wu, W. Cong, Z. Ning, In situ carbon supplementation in large scale cultivations of Spirulina platensis in open raceway pond, Biotechnol. Bioprocess Eng. 17 (2012) 93-99.

[11] Q. Huang, F. Jiang, L. Wang, C. Yang, Design of photobioreactors for mass cultivation of photosynthetic organisms, Engineering 3 (2017).

[12] D.J.T.M. Reinemann, J. Aquac. Eng. Fish. Res. 8 (1989) 33-37.

[13] C. Brindley, N. Jiménez-Ruíz, F.G. Acién, J.M. Fernández-Sevilla, Light regime optimization in photobioreactors using a dynamic photosynthesis model, Algal Res. 16 (2016) 399-408.

[14] M.R. Tredici, G.C. Zittelli, G.C. Zlttelli, G.C. Zittelli, M. Autotrofi, Efficiency of sunlight utilization: tubular versus flat photobioreactors, Biotechnol. Bioeng. 57 (1997) 187-197.

[15] D.O.O. Hall, F.G.A. Fernández, E.C.C. Guerrero, K.K.K. Rao, E.M.M. Grima, F.G. Acién Fernández, E.C.C. Guerrero, K.K.K. Rao, E.M.M. Grima, F.G.A. Fernández, E.C.C. Guerrero, K.K.K. Rao, E.M.M. Grima, Outdoor helical tubular photobioreactors for microalgal production: modeling of fluid-dynamics and mass transfer and assessment of biomass productivity, Biotechnol. Bioeng. 82 (2003) 62-73.

[16] G. Torzillo, P. Carlozzi, B. Pushparaj, E. Montaini, R. Materassi, A two-plane tubular photobioreactor for outdoor culture of Spirulina, Biotechnol. Bioeng. 42 (1993) 891-898.

[17] R. Bosma, J.H. de Vree, P.M. Slegers, M. Janssen, R.H. Wijffels, M.J. Barbosa, Design and construction of the microalgal pilot facility Algae PARC, Algal Res. 6 (2014).

[18] J. Chen, Y. Wang, J.R. Benemann, X. Zhang, H. Hu, S. Qin, Microalgal industry in China: challenges and prospects, J. Appl. Phycol. 28 (2016) 715-725.

[19] J.U. Grobbelaar, Microalgal Biomass Production: Challenges and Realities, (2010).

[20] D.R. Smyth, Helical growth in plant organs: mechanisms and significance, Development 143 (2016) 3272-3282.

[21] T. Steeves, I. Sussex, Patterns in Plant Development, Ed. Cambridge University Press, 1989, p. 392.
[22] D. Falstesr, M. Westoby, Plant height and evolutionary games, Trends Ecol. Evol. 18 (2003) 337-343.

[23] V. Sarlikioti, P.H. Visser, G.H. Buch-Sorlin, L.F. Marcelis, How plant architecture affects light absorption and photosynthesis in tomato: towards an ideotype for plant architecture using a functional-structural plant model, Ann. Bot. 108 (2011) 1065-1073.

[24] K. Pradeep Mohan Kumar, V. Vijayan, B. Suresh Kumar, C.M. Vivek, S. Dinesh, Computational analysis and optimization of spiral plate heat exchanger, J. Appl. Fluid Mech. 11 (2018) 121-128.

[25] C. Aguilar, M. González, A. Cifuentes, A. Cifuentes, Growth and accumulation of total carotenoids in two strains of Dunaliella salina Teod. (Chlorophyceae) from the northern and central coast of Perú, J. Chil. Chem. Soc. 49 (2004).

[26] E. Rojas, M. Ávila, G. Parada, ÁD. Acuícola, A.P. Brava, P. Magíster, F. De Ciencias, Aplicación de estrategias nutricionales y su efecto en el crecimiento en el cultivo continuo de Spirulina (Arthrospira platensis) Application of nutritional strategies and their effect in continuous culture of Spirulina (Arthrospira platensis), Aquat. Res. 40 (2012) 763-771.

[27] E. Calabrò, An algorithm to determine the optimum tilt angle of a solar panel from global horizontal solar radiation, J. Renew. Energy 2013 (2013) 1-12.

[28] E.M. Grima, F.G. Camacho, J.A.S. Pérez, J.M.F. Sevilla, F.G.A. Fernández, A.C. Gómez, A mathematical model of microalgal growth in light-limited chemostat culture, J. Chem. Technol. Biotechnol. 61 (1994) 167-173, https://doi.org/10 1002/jctb.280610212.

[29] E. Molina-Grima, F. García-Camacho, J.A. Sánchez-Pérez, F.G. Acién-Fernéndez J.M. Fernández-Sevilla, Evaluation of photosynthetic efficiency in microalgal cultures using averaged irradiance, Enzyme Microb. Technol. 21 (1997) 375-381.

[30] M.M. Morales-Amaral, C. Gómez-Serrano, F.G. Acien Fernandez, J.M. Fernández Sevilla, E. Molina-Grima, Outdoor production of Scenedesmus sp. in thin-layer and raceway reactors using centrate from anaerobic digestion as the sole nutrient source, Algal Res. 12 (2015) 99-108.

[31] G.I. Romero Villegas, M. Fiamengo, F.G. Acién Fernández, E. Molina Grima, Outdoor production of microalgae biomass at pilot-scale in seawater using centrate as the nutrient source, Algal Res. 25 (2017).

[32] M.R. Tredici, G.C. Zittelli, Efficiency of sunlight utilization: tubular versus flat photobioreactors, Biotechnol. Bioeng. 57 (1998).

[33] A. Fields, M.R. Tredici, G.C. Zittelli, Efficiency of sunlight utilization: tubular versus flat photobioreactors Wiley Inter Science, J. Abstract Drugs (2006) 3-5.

[34] E. Sierra, F.G. Acién, J.M. Fernández, J.L. García, C. González, E. Molina, Characterization of a flat plate photobioreactor for the production of microalgae, Chem. Eng. J. 138 (2008) 136-147.

[35] A. San Pedro, C.V. González-López, F.G. Acién, E. Molina-Grima, Outdoor pilot production of nannochloropsis gaditana: influence of culture parameters and lipid production rates in flat-panel photobioreactors, Algal Res. 18 (2016) 156-165.

[36] A. San Pedro, C.V. González-López, F.G. Acién, E. Molina-Grima, Outdoor pilotscale production of Nannochloropsis gaditana: influence of culture parameters and lipid production rates in tubular photobioreactors, Bioresour. Technol. 169 (2014) 667-676.

[37] C.B. Alías, M.C. García-Malea López, F.G. Acién Fernández, J.M. Fernández Sevilla, J.L. García Sánchez, E. Molina Grima, C. Brindley, M.C. Garcia-Malea, F.G. Acién, J.M. Fernández, J.L. García, E. Molina, Influence of power supply in the feasibility of Phaeodactylum tricornutum cultures, Biotechnol. Bioeng. 87 (2004) 723-733.

[38] A. Sánchez Mirón, M.C. Cerón García, A. Contreras Gómez, F. García Camacho, E. Molina Grima, Y. Chisti, Shear stress tolerance and biochemical characterization of Phaeodactylum tricornutum in quasi steady-state continuous culture in outdoo photobioreactors, Biochem. Eng. J. 16 (2003) 287-297.

[39] Z. Ma, K. Gao, Spiral breakage and photoinhibition of Arthrospira platensis (Cyanophyta) caused by accumulation of reactive oxygen species under solar radiation, Environ. Exp. Bot. 68 (2010) 208-213 https://www.sciencedirect.com/ science/article/abs/pii/S0098847209002512.

[40] A. Converti, A. Lodi, A. Del Borghi, C. Solisio, Biochemical Engineering Journal: cultivation of Spirulina platensis in a combined airlift-tubular reactor system, Biochem. Eng. J. 32 (2006) 13-18 https://www.sciencedirect.com/science/article/ pii/S1369703X06002178.

[41] B. Wang, C.Q. Lan, M. Horsman, Closed photobioreactors for production of microalgal biomasses, Biotechnol. Adv. 30 (2012) 904-912.

[42] E. Molina-Grima, J.M.F. Sevilla, J.A.S. Pérez, F.G. Camacho, A study on simultaneous photolimitation and photoinhibition in dense microalgal cultures taking into account incident and averaged irradiances, J. Biotechnol. 45 (1996) 59-69.

[43] E. Molina, J. Fernández, F.G. Acién, Y. Chisti, Tubular photobioreactor design for algal cultures, J. Biotechnol. 92 (2001) 113-131.

[44] X.W. Zhang, Y.M. Zhang, F. Chen, Kinetic models for phycocyanin production by high cell density mixotrophic culture of the microalga Spirulina platensis, J. Ind. Microbiol. Biotechnol. 21 (1998) 283-288 http://link.springer.com/10.1038/sj. jim. 2900581.

[45] G. Chini Zittelli, L. Rodolfi, N. Biondi, M.R. Tredici, Productivity and photosynthetic efficiency of outdoor cultures of Tetraselmis suecica in annular columns, Aquaculture 261 (2006) 932-943.

[46] C. Jiménez, B.R. Cossío, F.X. Niell, C. Jiménez, B.R. Cossío, F.X. Niell, C. Jiménez, B.R. Cossío, F.X. Niell, Relationship between physicochemical variables and productivity in open ponds for the production of Spirulina: a predictive model of algal yield, Aquaculture 221 (2003) 331-345.

[47] J.F. Sánchez, J.M. Fernández, F.G. Acién, A. Rueda, J. Pérez-Parra, E. Molina, Influence of culture conditions on the productivity and lutein content of the new strain Scenedesmus almeriensis, Process Biochem. 43 (2008) 398-405. 